\title{
What Are Dual Process Models? Implications for Cultural Analysis in Sociology ${ }^{1}$
}

\author{
Omar Lizardo \\ olizardo@nd.edu
}

\author{
Dustin S. Stoltz \\ dstoltz@nd.edu
}

\author{
Robert Mowry \\ rmowry@nd.edu
}

Marshall A. Taylor

mtaylo15@nd.edu

\author{
Brandon Sepulvado \\ bsepulva@nd.edu
}

Justin Van Ness

jvanness@nd.edu

\author{
Michael Wood \\ mwood3@nd.edu
}

\footnotetext{
${ }^{1}$ The idea for this paper first emerged in a fruitful discussion in a graduate seminar on "Culture, Cognition, and Society" led by the first author in the Spring of 2015 and in which all other authors were participants. Our names appear in alphabetical order to reflect the fact that this paper has been a collective endeavor through and through, from conception, to writing, to editing each other's words, although it did not took long for one of the authors to note the fact that, conveniently enough, this arbitrary convention still left the first author slot to be occupied by the more (institutionally) senior member of the group. In spite of that, this paper would never had come to fruition if it was not for Dustin Stoltz's vision, perseverance, and hard work (especially when it comes to assembling the citation data) and as such he deserves special thanks. Dustin was the first one to "see" a paper where the first author just saw a set of smart points usable to impress students in a seminar context. Dustin herded all of the cats, and made the seemingly quixotic attempt to write a seven-authored theory piece seem like a breeze. Of course, it was the intellectual input of all authors that ultimately made the paper more than the sum of its separate parts although we will spare you tired emergence analogies. Direct correspondence to Omar Lizardo, Department of Sociology, University of Notre Dame, 810 Flanner Hall, Notre Dame, IN, 46556. Email: olizardo@nd.edu.
} 


\begin{abstract}
In this paper we introduce the idea of the dual process framework (DPF), an interdisciplinary approach to the study of learning, memory, thinking, and action. Departing from the successful reception of Vaisey (2009), we suggest that intradisciplinary debates in sociology regarding the merits of "dual process" formulations can benefit from a better understanding of the theoretical foundations of these models in cognitive and social psychology. We argue that the key is to distinguish the general DPF from more specific applications to particular domains, which we refer to as dual process models (DPMs). We show how different dual process models can be applied to a variety of analytically distinct issues of interest to cultural sociologists beyond specific issues related to morality, such as culture in learning, culture in memory, culture in thinking, and culture in acting processes. We close by outlining the implications of our argument for relevant work in cultural sociology.
\end{abstract}




\section{Introduction}

\subsection{The Reception of Dual Process Models in Sociology}

Beginning with Vaisey's (2009) highly cited paper, theoretical and empirical considerations of cultural phenomena from a "dual process" vantage point have rapidly proliferated in American sociology. These include such highly debated issues as the linkage (or lack thereof) between discursively articulated "values" and action (Jerolmack and Khan 2014; Miles 2015; Summers-Effler, Van Ness, and Hausmann 2015; Vaisey 2008). In this way, the dual process imagery has become one of the primary conceptual tools used by sociologists, especially those who take seriously the link between cultural and cognitive processes (DiMaggio 1997; Cerulo 2010; Knorr-Cetina 2014), to motivate and theorize a now growing list of empirical studies (e.g., inter alia Vaisey and Lizardo 2010; Hoffmann 2014; Miles 2015; Srivastava and Banaji 2011; Longest, Hitlin, and Vaisey 2013; Leschziner and Green 2013). The growing influence of the dual process imagery post-Vaisey has also begun to generate some critical backlash, as analysts debate the implications of the approach for both theory (e.g., Swidler 2008; Abramson 2012; Lizardo and Strand 2010; Patterson 2014) and method (e.g., Pugh 2013; Jerolmack and Khan 2014; Vila-Henninger 2015).

To give a sense of the reception to Vaisey (2009), we conducted a citation analysis of all articles referencing the paper from the year of publication (2009) through 2014. The results, shown in Figure 1, confirm the impression that the article has indeed been influential. In those six years the paper received 174 citations for an average of about 35 citations per year. As the figure shows, the number of citations has increased over time; the paper received 16 cites in its first year and four times as many (64) in $2014 .^{2}$

We also coded the extent to which each of the citing papers engaged the Vaisey article. As it stands, the majority of citing articles offer only a passing acknowledgement

\footnotetext{
2 A Google scholar search of all articles published in American Journal of Sociology in their 114th volume puts Vaisey (2009) as the second highest cited article in the journal published that year only behind Breen, Luijkx and Pollak (2009).
} 
(usually a one-sentence nod) to the general dual process idea $(\sim 62 \%){ }^{3}$ This type of citation has grown the fastest, suggesting an increasing popularization of the dual process notion in the sociological literature. The second largest group $(\sim 18 \%)$ consists of "dual process adopters," meaning that they either elaborate on Vaisey's particular version of the dual process idea or use a broader dual process framework. The last two groups include those incorporating Vaisey (2009) in general reviews of recent work in cultural sociology ( 10\%), and those critiquing the dual process idea $(\sim 10 \%)$.

From this brief review it is clear that interest in dual process imagery has grown steadily among sociologists and shows no signs of slowing. Furthermore, while some engagement with the dual process idea remains on a perfunctory level, a significant number of scholars are grappling seriously with the opportunities and challenges afforded by the notion of dual process for research at the intersection of culture and cognition.

\subsection{Broadening Engagement with Dual Process Imagery}

There is no question that contemporary engagement with Dual Process Models (henceforward DPMs), including empirical applications and theoretical reassessments, has been generally salutary for cultural analysis. Recent use of DPMs has allowed scholars to expand and re-engage substantive areas that had not been seen as amenable to cultural analysis and the postulation of cultural processes (such as poverty and inequality: Vaisey 2010; Frye 2012), and has forced cultural theorists to revisit fundamental conceptual issues (Leschziner and Green 2013; Lizardo and Strand 2010; Vaisey 2008). In spite of these positive developments, we argue that the relatively limited theoretical development of the dual process idea, and the coinciding polemical critiques within sociology, reflect a largely truncated understanding of the breadth of substantive issues for which the general dual process imagery could be useful for sociologists. This overly narrow understanding has resulted in an under-appreciation of the scope of the framework and the range of empirical domains for which it is applicable.

\footnotetext{
${ }^{3}$ This category roughly corresponds to Sallaz and Zavisca's (2007: 26) notion of a "limited citation."
} 


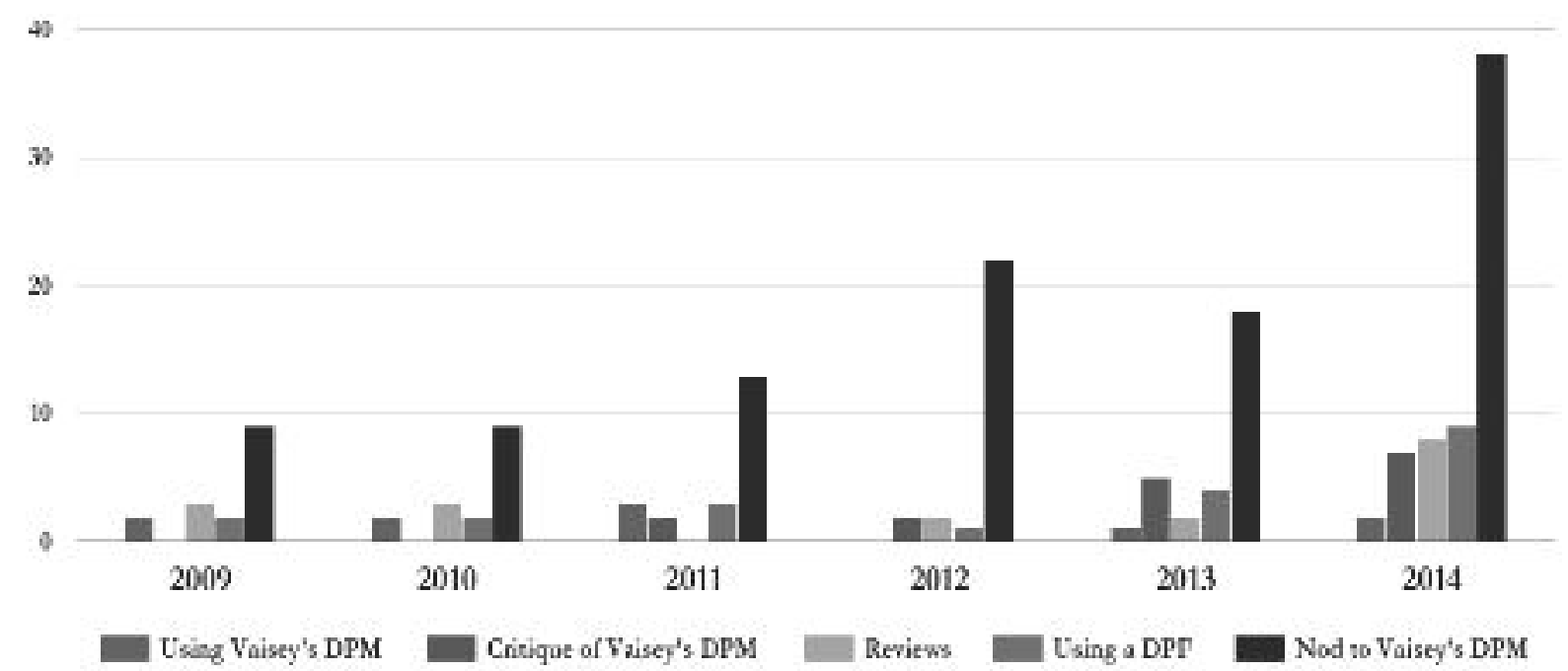

Figure 1. Citation analysis of articles citing Vaisey (2009). $N=174$. Source: Google Scholar. Only peer-reviewed journal articles are included.

For instance, both proponents and critics of DPMs in sociology generally fail to distinguish general dual process theory in cognitive psychology-which is largely uncontroversial (e.g., Smith and DeCoster 2000; Evans 2008)—from more specific empirical proposals derived from the application of specific DPMs to substantive areas or specific phenomena (which are subject to intra-disciplinary debate and contestation). Given the confusion and unproductive debate that results from this slippage, it is important both to clarify the difference between general dual process theories and specific DPMs as well as to specify the difference between distinct types of DPMs both in terms of domain of application and empirical scope (Smith and DeCoster 2000). Sociological critics of the general dual process imagery must know what they are critiquing, and advocates must know what they are advocating.

Given the increasing importance of dual process theory along with the conceptual confusion that attends it, we take up the task of reformulating what dual process models are and reintroducing them to a general sociology audience. To this end, we disaggregate and specify the general dual process framework, drawing on findings from the cognitive 
psychology of action and reasoning, moral psychology, and the social psychological study of attitudes and stereotypes. We do not intend to replicate previous introductions to DPMs which were crafted for an audience of psychologists (e.g., Sloman 1996; Smith and DeCoster 2000; Evans 2008; Chaiken and Trope 1999), but instead aim to present the full range of DPM choices available to cultural analysts interested in the culture-cognition link.

In the following sections, we show that in contrast to the overriding concern with dual process models of action in contemporary cultural sociology, there are four analytically distinct domains within which DPMs can be related to cultural processes. To that end, we elaborate four distinct phases of the enculturation cycle incorporating processes of cultural learning, encoding, and remembering, in addition to the "action" or "cultural use" phases typically engaged by Swidler (2001) and Vaisey (2008), among others. We believe all four of these phases, and associated processes, may be fruitfully conceptualized from the perspective of the dual process framework. Furthermore, we argue that these conceptualizations must be kept analytically distinct to forestall conceptual confusion and unwarranted extrapolation, and to facilitate application of the theory to empirical research.

\section{Dual Cognitive Processes Revisited}

\subsection{Dual Process Models versus the Dual Process Framework}

We begin by outlining some general considerations of dual process imagery in cognitive social science. Our analysis reveals that both critics and advocates of DPMs in sociology may have underestimated both the generality, descriptive power, and analytical potential of the general dual process perspective for addressing pertinent problems in contemporary cultural theory. We begin by making a distinction between what we refer to as the more general Dual Process Framework (DPF) and more specific instances of this framework to shed light on specific phenomena (e.g., attitudes, reasoning, moral judgment, etc.) in a given domain (DPM) (see Figure 2).

The DPF has become well-established in social, cognitive, and personality psychology 
(e.g., Brewer 1988; Sloman 1996; Haidt 2001; Strack and Deutsch 2004; Gawronski and Bodenhausen 2006; for reviews see Evans 2003, 2008; Smith and DeCoster 2000; Kahneman 2011 provides an accessible introduction). In this respect, the general DPF distinguishing between Type I and Type II cognition has become largely uncontroversial and accepted by the majority of psychologists and cognitive scientists (Shepherd 2011:127). ${ }^{4}$ Most of the debate today is not about the existence of multiple cognitive modes or processes but about their relative degree of independence or interaction (Evans 2008; Cunningham and Zelazo 2007; Mische 2010; Van Bavel, Xiao, and Cunningham 2012).

For this reason, the general DPF must be kept distinct from substantive claims pertaining to any one particular DPM as applied to a given set of lower-level phenomena (e.g. trust, reasoning, stereotypes, attitudes, morality, etc.), since these last may be subject to controversy, revision, and updating without this impinging on the overall validity of the general DPF. This is especially important for cultural analysts post-Vaisey. Analysts should acknowledge isolated applications and critiques of particular DPMs (e.g., the imagery embedded in Haidt's DPM of moral judgment from which Vaisey [2009] draws) as distinct from critiques of the entire DPF (see for example Mische 2010; Swidler 2008).

As an example of this problem, the incomplete reception of the DPF in cultural analysis risks of reducing all DPMs to a distinction between "cognition" and "emotion" (e.g., Pugh 2013) which is an erroneous contrast from the standpoint of cognitive science (Phelps 2006) and increasingly so in sociology (Cerulo 2010:119-122; Ignatow 2009). ${ }^{5}$ In contrast to this simplification, there are actually numerous analytical models, ranging widely in specificity, which utilize a DPF. For instance, Smith and DeCoster (2000:124) distinguish between at least nine distinct domain-specific DPMs within the larger DPF umbrella, while

\footnotetext{
${ }^{4}$ Some "single process" formulations do still exist but these are largely peripheral (see Burwell and Furtek 2008; Maquestiaux et al. 2010; Slotnick and Dodson 2005).

${ }^{5}$ Haidt (2001:818), for instance, explicitly states that "It must be stressed that the contrast of intuition and reasoning is not the contrast of emotion and cognition. Intuition, reasoning, and the appraisals contained in emotions ... are all forms of cognition." Despite being clear on this point, he later notes that "[i]n fact, since writing "The Emotional Dog,' I have taken upon myself a personal crusade of correcting people when they contrast 'affect' and 'cognition"' (2004:286).
} 
Chaiken and Trope's (1999) now canonical edited volume contains chapter-long entries on at least twelve distinct DPMs. In terms of post-positivist understandings of the dynamic of theory construction and theory change in science (e.g., Alexander [1982] 2014)_outlined in Figure 2-we may think of the general DPF as closer to the realm of general presuppositions, while the different dual process models belong to the realm of models, concepts and definitions, which in their turn approach the empirical pole when applied in particular research endeavors (e.g., experimental protocols, process-dissociation techniques, survey design, interpretation of ethnographic observations and interview data, etc.).

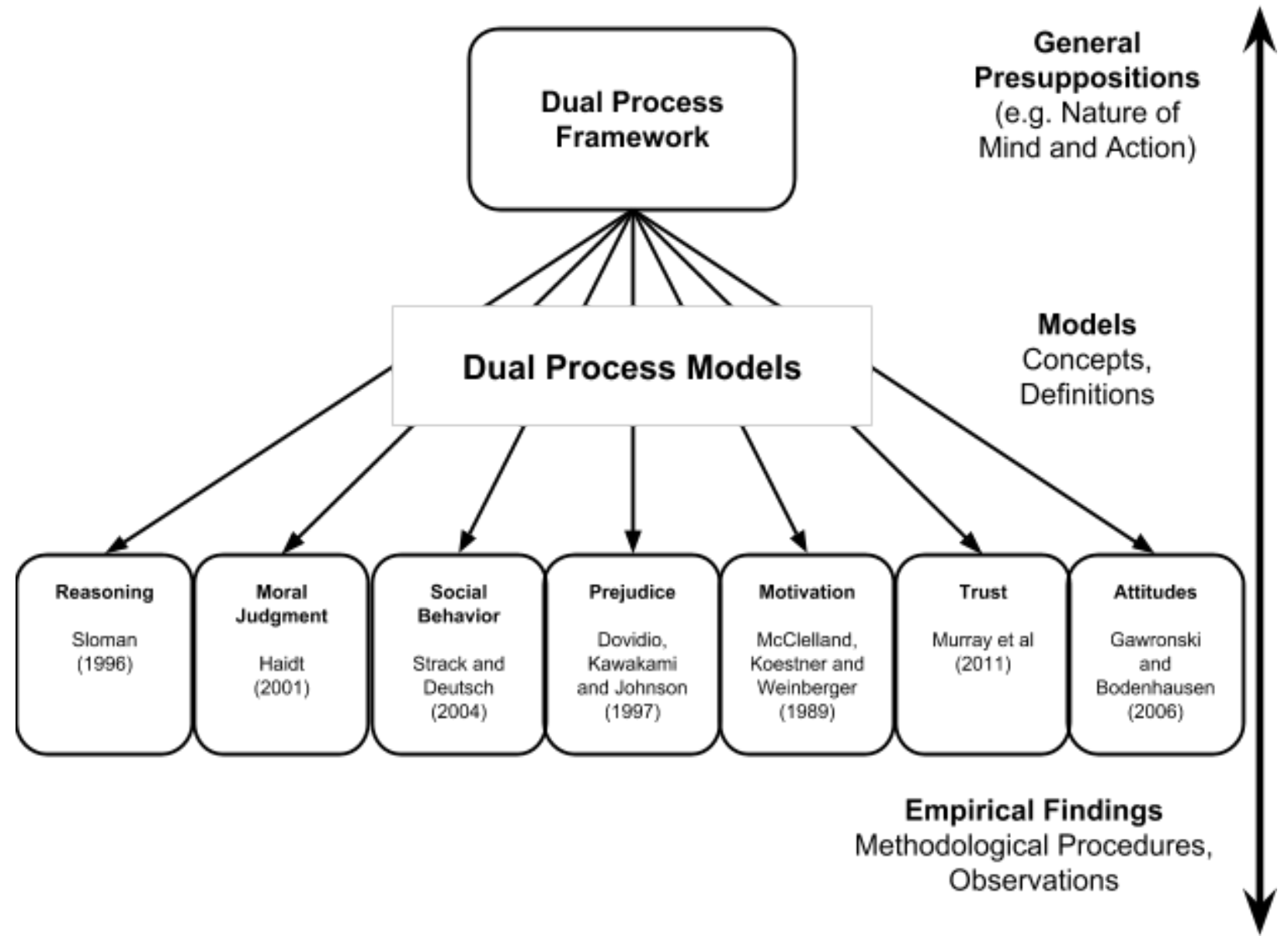

Figure 2. Alexander's ([1982] 2014:3) post-positivist epistemic continuum applied to the relation between the Dual Process Framework (DPF), specific Dual Process Models (DPMs) and Empirical findings in Cognitive and Social Psychology. 


\subsection{The General Dual Process Framework}

The general DPF, in various manifestations, emerges throughout the history of social scientific inquiry, including sociology and economics, as a solution to the debate regarding whether basic cognitive processes involve the explicit logical manipulation of symbols, or implicit, parallel and distributed pattern construction and recognition. ${ }^{6}$ The answer, according to proponents of the DPF, is that cognition can be both sequential and parallel, symbolic and distributed. We refer to these two types of cognition in the DPF as Type I and Type II, following the now standard convention (Evans 2008; see Table 1). Often, when cultural analysts in sociology make a distinction such as "implicit and explicit," "conscious and unconscious," or even "fast and slow," they are helping themselves to a key premise of the DPF.

Although there is a consensus regarding the dual nature of cognition (Kahneman 2011), specifying the composition, distinction, and interaction of the two types of cognitive process is an ongoing project (Evans and Stanovich 2013; Cunningham and Zelazo 2007) resulting in a rapidly growing number of domain-specific DPMs. What all DPMs share, however, is the presupposition that Type I cognition is characterized by slow learning, associative structure, rapid, automatic, and effortless deployment in thinking and action. Type II cognition, on the other hand, is characterized by fast learning, propositional structure, slow, deliberate, and effortful deployment. More importantly, these two processes can be dissociated (both in the laboratory and in ecologically natural settings), producing contradictory outputs for the same pragmatic task (Gawronski and Bodenhausen 2006; Smith and DeCoster 2000; Sloman 1996).

\footnotetext{
${ }^{6}$ For instance, Vaisey (2009) references the contemporary sociological work of Anthony Giddens and Pierre Bourdieu, and Vaisey (2008) also links the dual-process framework to the habit theory of Aristotle.
} 
Table 1. Dual Process Models of Cultural Learning, Storing, Thinking, and Acting.

\begin{tabular}{lccc}
\hline Domain & $\begin{array}{c}\text { Enculturation } \\
\text { Phase }\end{array}$ & Type I & Type II \\
\hline \multirow{4}{*}{ 1. Learning } & Acquisition & Practical/ & Conceptual/ \\
& of Culture & Embodied/ & Symbolic/ \\
& Implicit/ & Explicit/ \\
& & Slow-Learning & Fast-Learning \\
\hline \multirow{4}{*}{ 2. Remembering } & Storage & Nondeclarative/ & "Know that"/ \\
& of Culture & Distributed & Seclarative/ \\
& & Representation & Representation/ \\
\hline 3. Thinking & & "See that"/ & "Reason why"/ \\
& Processing & Rapid and Effortless/ & Slow and Effortful/ \\
& of Culture & Associative-Based/ & Rule-Based/ \\
& & Parallel Processing & Sequential Processing \\
\hline \multirow{3}{*}{ Acting } & Use & Impulsive/ & Reflective/ \\
& of Culture & Automatic & Controlled \\
\hline
\end{tabular}

At the most general level, dissociation of the two processes provides the most convincing evidence they are distinct. ${ }^{7}$ Such experimental strategies exploit that fact that Type II is both slow to deploy and relatively limited in capacity (Hagger et al. 2010). In experiments that exploit speed, such as implicit bias tests (e.g., Greenwald et al. 2009), priming studies (e.g., Katz and Hass 1988), or stereotype threat studies (e.g., Steele and Aronson 1995), participants are exposed to stimuli that activates Type I processes which are too fast to be noticed or bypassed by Type II processes. Experiments using effort to dissociate the processes often instruct some participants to complete a task requiring controlled and deliberate reasoning before taking a subsequent test. In these experiments, resources upon which Type II processes depend are usually depleted and thus temporarily hampered for participants asked to complete the extra tasks (e.g., Hagger et al. 2010; Yam, Chen, and Reynolds 2014). ${ }^{8}$ The experimental evidence suggests that these processes are

\footnotetext{
${ }^{7}$ Convergent neurophysiological evidence also supports this contention (Cunningham and Zelazo 2007).

${ }^{8}$ For fruitful empirical applications of both of these approaches in cultural analysis see Miles (2015) and Srivastava and Banaji (2011).
} 
distinct yet may operate in tandem, and are therefore recruited at all phases in which people learn, store, and use culture for thinking and action.

\subsection{The Dual Process Framework and the Enculturation Process}

In outlining what we mean by the enculturation process it is important to note that, rather than being confined to a single delimited stage, essentially all stages of the enculturation process, from acquisition, to storage, to thinking, and action can be theorized from a DPF perspective. Here we skirt the more fine-grained, domain or task-specific classifications of DPMs in cognitive psychology (e.g., Chaiken and Trope 1999). Instead, we propose four analytically distinct DPMs at a higher level of generality that we believe is more useful for cultural analysis in sociology. A DPF conception of the enculturation process links distinct pathways and mechanisms of cultural exposure and transmission to correlatively distinct ways in which culture becomes "stored" in long-term memory (Smith and DeCoster 2000), cognitively processed, and ultimately linked to action.

Following cognitively-motivated theories of cultural meaning, we conceive of enculturation as a process of internalization of cultural, experiential, and material patterns encountered in the external world via a developmental learning process with resultant consequences for cognition and action (D'Andrade 1981; Strauss and Quinn 1997). We conceive of internalization, in its turn, as the modification (e.g., strengthening of links) of neural pathways (Bloch 1991), which entails the encoding of cultural knowledge in distinct, long-term memory systems (Whitehouse 2004). A DPF conception of the enculturation process connects the distinct ways in which culture is internalized by people to correlatively distinct ways in which cultural representations are accessed and thus link into action (Strack

and Deutsch 2004). DPMs in cognitive and social psychology may thus be also thought of as "dual state" models since they attempt to theorize systemic diversity of both process (cultural access and use) and state (cultural encoding) variables (Smith and DeCoster 2000).

In this last respect, it is important to note that for every cultural "element" at the personal level there is a "pragmatic task" that people use that cultural element to accomplish 
(Patterson 2014). This links theorized diversity in culture's encoded format to diversity in its use. This is an insight that is shared by the American pragmatists (e.g., Dewey, James, Peirce), social psychologists influenced by the Gestalt school (e.g., Kohler, Lewin), and contemporary social and personality psychologists (e.g., Bargh and Ferguson 2004). For example, attitudes are knowledge structures used for evaluation purposes; evaluations may in turn be used for a variety of goal-related actions at both the individual and institutional levels (Lamont 2012). In the same way, categories are used for purposes of classification, with classification influencing the way that we respond behaviorally and affectively to the objects so classified (Douglas 1966), and linking to institutional structures for sorting persons, objects, and situations (Douglas 1986). Finally, values are used for goal setting and thus action motivation in both the short and medium term (Eccles and Wigfield 2002). The motivation of action by values, in its turn, helps to account for the relatively consistent behavioral differences between individuals within the same social group (Miles 2015), across groups at a given time, and between the members of the same social group over time (Inglehart 2006; Schwartz 2006).

\section{Learning, Remembering, Thinking, and Acting}

DPMs have been developed to specify distinct pathways through which culture is acquired in "complementary learning systems" models (e.g., "fast" via a low number of exposures, or "slow" via repeated exposures [McClelland, McNaughton and O’Reilly 1995]). In the same way, we find a family of DPMs concerned with theorizing and specifying the distinct formats or states in which the culture so-acquired is stored. We can thus differentiate culture as declarative, symbolic "rules," from culture as nondeclarative, sub-symbolic associations between conceptual primitives (Sloman 1996). We also find DPMs that are concerned with theorizing how distinct cognitive processes operate on internalized culture depending on the way in which encoded cultural information has been stored. We may thus differentiate between cultural resources that allow persons to effortlessly "see that" from 
those that permit them to "reason why" (Margolis 1987). Finally, DPMs concerned with the culture/action linkage point to the fact that culture may link to practical "action" in two ways: either via a reflective process in which action is monitored and controlled via a deliberative channel or via an "impulsive" process in which action occurs independently of the will and intention of the agent (Strack and Deutsch 2004).

In next four sections, we elaborate on the implications of the DPF for studying processes of cultural acquisition, storage, processing, and action. Because cultural sociologists tend to privilege Type II cognition (Vaisey 2009; Jerolmack and Khan 2014; Pugh 2013) and generally bring in Type I cognition only residually, if at all, there are many important cultural elements, processes, and consequences that remain to be dealt with empirically (Bloch 1998; Shore 1996). Rather than a critique of the limitations of our collective methodological tools, however, these sections should be read as a guide for linking the diverse data and methods within sociology to sound claims about the role of culture in the sort of interactional, institutional and collective processes of interest to sociologists. More importantly, cultural analysts should take note of the vast untraversed terrain of cultural inquiry opened up by the DPF, ripe for sociological investigation.

\subsection{Culture and Learning}

Humans are born cognitively underdetermined (Berger and Luckmann 1966:65-66; Geertz 1973:68), insofar as our prenatal neurological hardwiring alone would leave us unable to well navigate the world. However, humans surpass all other primates in the extent to which we learn from each other and our environments (Tomasello 1999; Parker and McKinney 1999). It is now a consensus position in cognitive social science that cultural development constitutes an integral part of cognitive development (Shore 1996). This is a topic that has also been central for sociologists since Durkheim's ([1915] 2008) attempt to propose a theory of the social origins of the categories of understanding, and Parsons's "solution" to the utilitarian dilemma by postulating a cultural learning process productive of shared values (cognitive "internalization"; see Parsons 1964). With certain (mostly implicit) 
exceptions, sociological theories privilege a single learning process; either explicit (e.g., Parsons 1951) or implicit (Bourdieu 1990). Here we propose that cultural learning can be conceptualized from a dual process perspective.

To begin, it is important to consider briefly what learning is not. In short, "any view that construes learning as a process of pouring of information into a passive, 'floppy disk' brain, where it is then absorbed and stored in memory, is a totally outmoded and erroneous view" (Laughlin et al. 1992:66; cited in Shore 1996:7). ${ }^{9}$ Cultural learning does not consist of passive and homogeneous reception of bits of information. People not only respond differently to stimuli, but also take in information in analytically and empirically distinct ways. As this implies, the task of the cultural analyst as it relates to cultural acquisition is in no way straightforward (Bloch 1998). In what follows, we review the recent insights from cognitive social science with a view of highlighting their relevance for contemporary theoretical debates as to how people become "encultured."

So, how do we learn? The more detailed answer is that how we learn depends upon what we are learning and what we are doing while we are learning. There exist two broad types of cultural learning, and these (not surprisingly) align with the Type I and Type II distinction typical of DPF inspired models. The first has been called explicit learning (e.g., Hendricks et al. 2013) and generally corresponds to a Type II process as presented in Table 1. Explicit learning is generally considered to be effortful, only able to handle delimited ("chunked") cultural elements, and requires an active, attentive learner. This type of learning has also been referred to as "rule-based" or "propositional learning" given its dependence on the reflexive consideration of explicitly stated beliefs or statements on the part of the learner during the process (Smith and DeCoster 2000; Gawronski and Bodenhausen 2006).

The second type of learning — implicit learning (Reber 1993)—corresponds to a Type I process which is less effortful and can occur without the active attention of the learner. In

\footnotetext{
${ }^{9}$ Although this clearly rules out naive rational choice models, many areas of sociology are guilty of deploying this faulty view of learning.
} 
contrast to explicit learning, implicit learning may generate associations between traits and concepts based on simple temporal and spatial contiguity in experience, which is why it has also been referred to as "associative learning" (Gawronski and Bodenhausen 2006). In this respect, it is important to keep distinct learning processes that operate via the formation of new associations gradually built and strengthened via repeated experiences, and learning via rules which can be explicitly encoded into memory after a single exposure experience. While the former are not necessarily shared and do not require symbolic encoded, the latter must perforce be explicitly represented in public symbols (Smith and DeCoster 2000:111)

Though researchers are divided over whether or not learners must be intentionally attentive during the acquisition of cultural practices (Hendricks et al. 2013; see also Moors and De Houwer 2006 for a detailed discussion), research on "automaticity" in psychology (Bargh and Chartrand 1999) suggests that the implicit learning of associations can happen largely via low resource, attention-independent "automatic" processes. More importantly, this research suggests that a good chunk of cultural acquisition happens via these implicit pathways (Bloch 1991; Shore 1996). This supports the contention, foundational to practice theory, that we may "know more than we can tell" (Polanyi [1966]2009: 4).

Skill acquisition (e.g., Wacquant 2004) is one of the prototypical examples of a Type I enculturation process. These have figured prominently in both classical (e.g. Sudnow 1978) and more recent (e.g. Wacquant 2004) "apprenticeship ethnographies" in which the sociological observer attempts to become encultured into a practice or lifeworld via a Type I process. As the anthropologist of practice Gísli Pálsson notes, both fishing and doing ethnography mean "not mechanistically to internalize a stock of knowledge but to be actively engaged with an environment" (1994:901). In a similar vein, Maurice Bloch argues that, as it relates to complex tasks, becoming an expert

...involves the construction of a cognitive apparatus [i.e., schema] dedicated to cope with this sort of task. The establishment of that apparatus is slow, and while it is in construction there is significant improvement; however once it has been set up no further improvement 
becomes possible. A chunk or apparatus concerned with a familiar activity has thus come into existence in the brain as a result of repeated practice. (Bloch 1991:188)

Type I learning processes are also behind the acquisition of the so-called "implicit associations" that have become the bread and butter of social and cognitive psychology for the last two decades (Greenwald and Banaji 1995; for discussion of implications for cultural sociology see Shepherd 2011). In the same way, learning implicit categorization criteria from a large number of exposures to exemplars, allowing people to classify via inarticulable "family resemblances" rather than explicit rules, happens via the same (Type I) process (McClelland et al. 1995).

A growing body of evidence indicates that the processes underlying the two types of learning are distinct, dissociable, and are put to use across situations in variable ways which may complement or interfere with another (Cohen and Squire 1980; Sun, Terry, and Slusarz 2005). For example, skill acquisition, discussed above, is largely influenced by what an individual is doing while learning, information obtained from available feedback, and environmental conditions during the learning process (Fu and Anderson 2008; Sun, Slusarz, and Terry 2005). Taken together, this research suggests that as the complexity of the cultural learning task increases, the more Type I processes will be implicated (Lee 1995). In fact, if learners of a complex motor skill attempt to consciously focus on their movements or even verbalize rules for task completion, this can hinder the acquisition of the skill (Chauvel et al. 2013; Wulf, McNevin, and Shea 2001; Wacquant 2004). As a result the (natural, built, and social) environment automatically-engenders Type I cultural acquisition, which is largely outside conscious reflection (Bourdieu 1990).

Although we consider it useful to present the DPM of cultural learning as analytically distinct from the other models presented, it is in the context where a knowledge or a skill is to be changed (e.g., retooling, or "unlearning to learn") that it bleeds across distinctions. For instance, Fu and Anderson (2008) find that, after a skill is learned, the ability to adapt the skill when conditions change depends again upon the memory system involved (see next 
section). Persons learn to adjust previously acquired skills slowly and are prone to error if Type II processes are active during the adjustment learning period, learn to adjust their skill quickly when Type I processes are primary, as long as there is feedback about skill performance. This highlights that Type I culture, compared to Type II, takes longer to acquire through repeated practices, is more efficient when the task involves learning complex cultural elements (Bloch 1991), automatically incorporates more information from the environment, and it is more difficult to change once acquired (Lizardo and Strand 2010).

\subsection{Culture and Memory}

DPMs developed for purposes of dealing with issues of "cultural storage" are best thought of as DPMs of distinct memory states rather than as models of the cognitive processes that operate on those states (see next section). ${ }^{10}$ According to this family of DPMs, memory is divided into two main types, most commonly referred to as "declarative" and "nondeclarative" memory. Declarative memory (Type II) consists of consciously accessible memories of facts, symbols, and events, while nondeclarative memory (Type I) consists of relatively less accessible procedural knowledge, habits, and dispositions. The two kinds of memory are sometimes distinguished as "knowing that" and "knowing-how" (Ryle 2002), or "explicit" and "implicit" memory (Schacter 1987, 1994). Applied to cultural sociology, the DPM of memory rejects the claim that culture can be studied singly as explicit knowledge (declarative memory) and directs researchers to also study culture in its alternative, nondeclarative forms.

Declarative (Type II) memory is divided into three types: episodic memory, or the details and content of specific, time-bound events (Tulving 1983), semantic memory, which includes impersonal, propositional facts and conventional meanings of words (Squire 1992), and autobiographical memory (Brewer 1986), which uses both episodic and semantic memory to generate a personal life narrative (Conway and Pleydell-Pearce 2000), incorporating temporal order within episodes and between personal episodes (Glenberg 1997:33). We can

\footnotetext{
${ }^{10}$ For a related content-process distinction see Shepherd (2011:124).
} 
say that declarative memory is "accessible" because one can think about and make explicit facts, episodes and personal narratives, and we can also say that it is "representational" because they offer ways to model the external world. When social scientists record the words people say in interview settings, they are recording some form of declarative memory. This might be semantic memory in the form of facts of a personal ("I have seven siblings") or evaluative ("having two married parents is good for children") nature, episodic memory in the form of first-hand accounts ("It was cold, dark and dusty"), or autobiographical memory in the form of personal narratives ("the warehouse debacle happened just after my seventh sibling was born").

Nondeclarative (Type I) memory includes procedural memory (Cohen and Bacdayan 1994), or stored traces of skills and habits, as well as dispositions arising from things like priming, classical conditioning, and associative learning (Tulving and Schacter 1990). We can say that nondeclarative memory is "inaccessible" because it is impossible to directly recall it in a discursive way. For example, a person may talk about how to ride a bike, but the actual skill cannot be retrieved and transmitted like a declarative memory (Polanyi 1958). Similarly, a person may notice that she has a particular aversion to people of color, but knowledge of the aversion is limited to that. She may confabulate theories about the aversion, but the aversion itself is nonrepresentational and thus "implicit" (Greenwald et al 2009). ${ }^{11}$ More importantly, a person may report an explicit attitude or evaluation (e.g., positive affect toward Hispanics) that is the opposite of her implicit evaluation (e.g., associating Hispanics with criminality) and she may have little knowledge of this discordance (Wilson, Lindsey and Schooler 2000).

While the two types of memory are distinct, they work in parallel, as many

\footnotetext{
${ }^{11}$ Declarative (Type II) and nondeclarative memory (Type I) roughly correspond with Type II and Type I learning processes described above, respectively, but there is an important exception. Nondeclarative memories typically develop gradually over time through the slow-binding (Type I) learning process, but they can also develop rapidly through a "one-shot" or "flashbulb" learning (Conway 1995). This is the case for traumatic or intensely affective experiences, which can create durable associations that shape future cognitions and behavior (Whitehouse 2004). However, such memories are not necessarily more accurate, but rather engender more confidence in actors regarding their accuracy (Talarico and Rubin 2003).
} 
experiences implicate both declarative and nondeclarative memory. A child who is bitten by a dog may acquire declarative knowledge (the fact of the dog bite and the episodic knowledge of it) and possibly also nondeclarative knowledge in the form of cynophobia (Squire 2004:174). Similarly, a skilled performer may have the nondeclarative procedural knowledge to perform the task, as well as declarative vocabulary to explain what she is doing (e.g. Sudnow 1978). However, such a coupling is not necessary, and therefore it is common to find skilled experts who lack the vocabulary to effectively instruct others (e.g., Wacquant 2004).

Practically speaking, this dual understanding of memory requires researchers to specify which form they are accessing via their data (Bloch 1998). Catch-all definitions of personal culture which indiscriminately mix nondeclarative and declarative memory muddle explanations of cognition and action (Whitehouse 2004). Personal culture consists of both non-representational skills, habits and associations, and (more or less) representational episodic and semantic information. Thus, rather than looking at "culture" as a single set of elements or collapsing "culture" into a single dimension (such as values, beliefs, or habits), particular DPMs of cultural storage identify the precise formats that people use for the pragmatic tasks of thinking and action in problem-solving contexts (Gross 2009). This reconsideration may pose severe challenges to some existing theories of culture and action (especially those that would directly link semantic knowledge to habits and associations), but the promised payoff is greater clarity in understanding what persons are doing with what type of culture and where. ${ }^{12}$

\subsection{Culture and Thinking}

The third domain of DPMs we review can be broadly conceptualized as oriented toward questions of "thinking," or the "processing" of culture once learned and stored. The key concern here is the relationship between parallel and sequential forms of thinking (Strauss

\footnotetext{
${ }^{12}$ Regarding methodology, DPMs of memory attune researchers to the fact that particular methods are limited in the degree to which they can access or draw out one form of culture or another (as noted by both Vaisey 2009-a sociologist_ and Bloch 1998_ _ an anthropologist_in a different context).
} 
and Quinn 1997; Bloch 1991; Smith and DeCoster 2000). In short, this family of DPMs deals with the question: How do we "think with" our cultural knowledge? This question is generally addressed by juxtaposing associative thinking with rule-based thinking. Or, as a complement to "knowing-how" and "knowing that" in the previous DPM of storage, the dual process model of culture in thinking can be divided into "seeing-that" 13 and "reasoning why" (Margolis 1987; see also Martin 2010:233ff).

We suggest that although Vaisey (2009) advocates a dual process model of culture in action, the DPM cultural sociologists generally rely on when they refer to "automatic cognition" and "deliberate cognition" (e.g., Leschziner and Green 2013; Vaisey 2008; cf. Haidt 2001, 2005) is, in fact, not a DPM of how and why actors "do things," but instead a DPM of how and why actors deploy a given cognitive process in the way they do. ${ }^{14}$ As such, we conceptualize this family of DPMs — the one most recognized within sociology—as a dual process model of culture in thinking. We propose that we can gain analytical purchase by distinguishing between processes of thinking and doing; to that end, we move away from the generic focus on "automatic" and "deliberate" cognition (e.g., Leschziner and Green 2013). Instead, we think of this DPM in terms of associative information processing (Type I culture in thinking) and rule-based information processing (Type II culture in thinking). The association-rule distinction in human cognition naturally follows from psychological and neuropsychological research on learning processes and memory states, as touched on in the previous two sections. Where this DPM is unique, however, is its focus on processing-i.e., its concern with how, when, and why actors draw on cultural knowledge already acquired

${ }^{13}$ This is not to suggest that the Type I thinking is entirely visual. Not only does it incorporate all sensory modalities, but generally does so in tandem, through a logic of Hebbian learning whereby all modalities practically relevant to identifying objects and possible actions are activated together (see also Barsalou 1999:585).

14 This is related to Gawronski and Bodenhausen's (2011:73) distinction between "operating principles" (thinking) and "operating conditions" (doing). Operating principles refer to "definitions of what a particular process is doing (e.g., activation, valuation)"; operating conditions, however, "represent empirical claims about when the process is operating" (p. 73, emphasis in original). In the case of a cognitive process such as valuation, for instance, cultural sociologists have by and large focused on questions of how (e.g., rapidly or slowly) actors assign value to a given entity and less on questions of when - that is, in what particular impulse- or reflection-oriented action environments-they assign value to the entity in the first place. 
through conceptual or practical learning stored as declarative or nondeclarative representations in the respective memory systems.

Type I culture in thinking refers to "the form of pattern-completion or similarity-based retrieval from the [practical] slow-learning [schematic] memory system, cued by salient features of the input" (Smith and DeCoster 2000:111). It implies the "spreading [of] activation" among cognitive structures that "bind" to one another via repeated patterns of coactivation in the past (Strack and Deutsch 2004). Put another way, associative thinking is the dominant "processing mode" (Smith and DeCoster 2000:110) for utilizing information learned via subconscious observational or bodily repetition ("implicit learning" as noted above) and stored in a nondeclarative representation not immediately retrievable through deliberate means (although this linkage is an empirical matter). Type I culture in thinking thus involves automatic pattern-recognizing, pattern-filling, and pattern-updating, and is a "top-down" process insofar as it involves "assimilat[ing] data to existing prototypes" (Martin 2010:233).

Rule-based information processing, by way of contrast, is the dominant form of Type II culture in thinking. This involves a reliance on "symbolically represented rules that are structured by language and logic" and are assigned truth-values (Smith and DeCoster 2000:111). Thus type II culture in thinking comes closer to the Weberian ideal type of cultural organization as a form of "logical logic" (Swidler 2001:206). Due to its encoding in (relatively) context-free symbols, Type II culture can be used for "offline" processes of reasoning, planning, imagining, anticipating, remembering, justifying, and narrating outside of the action contexts under which it was initially acquired. In this sense, Type II culture in thinking-or "bottom-up" processing (Martin 2010:233) —is the paradigmatic form of cognition of interest to cultural sociologists (often to the exclusion of Type I). However, as one of the primary presuppositions of the DPF, Type II thinking is both slow (in terms of time-scale) and limited in terms of capacity (Martin 2010: 235-230).

Type II thinking is slower because it relies on serial processing-that is, only 
manipulating or concatenating very few discrete "chunks" of information at a time. Once, this serial manipulation was believed capable of processing seven pieces of information, plus or minus two (Miller 1956), but now this number is believed to be closer to four, plus or minus one (Knorr-Cetina 2014:35; Dietrich 2004:752-53). As this type of cultural information processing is not necessarily activated by the current action situation - it usually occurs "offline" - it requires the "suppression" of both stimuli from the current context and the automatic cognitive responses (i.e., Type I culture in thinking or even Type I culture in action as detailed below) to environmental input (Glenberg 1997). ${ }^{15}$ Therefore, such Type II thinking tasks as planning a shopping list for tomorrow, or remembering yesterday's news will "deplete" the limited resource available (Baumeister et al. 1998; Hagger et al. 2010). This has the effect of impoverishing subsequent Type II information processing. ${ }^{16}$ Taken together, this leads us to a conclusion already widely agreed upon among sociologists: Parsonian internalization of entire cultural systems of explicit norms and values, which are then consciously understood, deliberately followed and require "effort" to conform to, is an empirically unattainable end state (Martin 2010; Silver 2011).

Despite the limitations of Type II cultural processing outlined above, rule-based symbolic thinking is the sin qua non of cultural sociological research and theorizing insofar as it is a useful heuristic (and, in the case of formal rules such as laws, an empirical reality) for understanding how actors deliberate, come to decisions, make sense of everyday life, and, more generally, "reason why" (Turner 2007). As such Type II culture in thinking is not new to cultural sociology, but a sole focus on it has unduly restricted theoretical development in the field to deliberate reasoning (Type II) to the exclusion of intuition (Type I). Nonetheless, researchers in sociology-evidenced in much of the work cited above-tend to presume that the line between "deliberate" and "intuitive" reasoning, or the processing of "explicit" and "implicit" rules, is fluid (Leschziner and Green 2013). This leads to the problematic

\footnotetext{
15 Taken to excess, this form of thinking would be "dangerous," because, for instance, "properties [of the environment] that should be controlling action (such as walking) are ignored” (Glenberg 1997:10).

${ }^{16}$ There is a growing body of empirical work in social psychology on the exact limitations of Type II processes, and how once "depleted" this resource can be "replenished" (see Hagger et al. 2010 for a meta-analysis).
} 
inference that such constraining "rules" are taken-for-granted until self-reflection, or a problem-situation, brings them to the surface. The DPM of culture in thinking suggests that the sort of attention-focusing and sense-making that deploys implicit associations, and those that use explicit "rules" are, in fact, distinct (Stoltz and Taylor 2015).

As noted above, Vaisey's argument has largely been interpreted as a DPM of culture in action. However, as suggested at the outset, we argue that the concepts of "deliberate cognition" and "automatic cognition"-which Vaisey (2009:1675) links to “"discursive' and 'practical' modes of culture and cognition," respectively-best approximate how actors process cultural knowledge rather than use cultural knowledge (although to the extent to which researchers see "thinking" as a form of "use" this distinction may be semantic). To be sure, Vaisey addresses a number of outcomes (indicators of "action") whose variation is perhaps better accounted for through one-shot forced-choice answers to survey responses (indicators of automatic cognitive processing) as opposed to discursive answers to open-ended interviews (indicators of deliberative cognitive processing).

However, we contend that this approach conflates (offline) reported "outcomes" (e.g., consuming alcohol or drugs) with (online) "action" (the social process by which these materials come to be consumed). In this respect, we suggest that the distinction between "outcome" and "action" is consequential for theory and research. By conflating outcome and action and, subsequently, thinking with action, we risk missing what is cognitively distinct about each. For instance, perhaps it is the case that justifying or motivating the use of alcohol or drugs in Vaisey's sample is unique from the ways in which respondents in the sample acquire and consume them. In this respect, and following the spirit of Vaisey's (2009) approach, we believe that the question of whether a given form of culture in thinking (e.g., Type I or Type II) is or is not connected to action-based outcomes should always be an empirical and not an analytical question. After all there do exist programs of research in cognitive social science that, contra-Vaisey, do proclaim the existence of strong correlations between Type-II culture in thinking (e.g., "reasoned action") and behavioral outcomes (e.g., 
Fishbein and Azjen 2011).

\subsection{Culture and Action}

The final DPM is where the action is-literally. Although the argument could be made that thinking or judgment is a type of action (Ryle 2002), we find that analytically distinguishing thinking (as described above) from what people actually do in situations leads to the realization that cultural analysts very often study the former at the expense of the latter. ${ }^{17}$ To put it another way, aside from some ethnographers (e.g., Wacquant 2004; Summers-Effler 2010; Pagis 2010; Khan 2011), the bulk of current work in cultural sociology focuses on what people say (or what they say they do), rather than what they actually do (Jerolmack and Khan 2014).

While the theory and research relating DPMs to action is not yet settled, the notion that dual process models can be extended to theories of action is not controversial (Strack and Deutsch 2004). Analytically separating the thinking from action DPMs is important because cultural analysts very often rely on data that get at (usually indirectly) culture in thinking and then attempt (with mixed success) to theoretically extend arguments to culture in action; notably, this is an analytical move - the data themselves are not data of action (e.g., Swidler 2001; Vaisey 2008, 2009). Thus, despite Lamont and Swidler's claim that a "skilled interviewer could evoke a variety of interactional settings, social contexts, and institutional situations and can probe their meanings in ways ethnography can rarely do" (2014:160) it must be recognized that this evocation, however, is still simulated and imagined and is not actual action taking place in these settings, contexts, and situations (Eliasoph and Lichterman 2003:743). No degree of skill or prior experience can change the fact that in an interview the data are inherently constrained to thinking about imagined or recollected situations.

\footnotetext{
17 This development is largely a consequence of interviews being conflated with ethnographies and the tendency for ethnographers to use interview methods which set primacy to discourse in naturalistic settings over interaction. In order to theorize culture in action, ethnographers should take their cue from Goffman (1989) and privilege what people do over what they say, so that "perspectives on action are not confused for "perspectives in action" (Snow and Anderson 1987). Discourse is valuable for an ethnographer in so far as it is triangulated with other sources of data (e.g., Snow and Anderson 1987:1343).
} 
A key impediment to further progress on these issues is analytical, and comes from the presumption that if a given line of activity is not "reasoned" or preceded by thought or a judgment it is ipso facto not "action" (Campbell 2009). If this was true, then the discussion of DPMs for cultural sociologists could be restricted to the culture in thinking work dealt with in the previous section, and that is precisely how most people engage with Vaisey (2009). However, this Parsonian bias is both theoretically fallacious (since it tries to rule out what is or is not action via armchair gerrymandering) and empirically misleading. Work in the psychology of action has uncovered a variety of systematic types of action that share all of the Parsonian goodies, such as goal directedness, rational choice of means and so on, that are set off without having to be preceded by elaborate intentions, judgments or overt decisions based on reflective reasoning processes (Strack and Deutsch 2004). In particular, we argue (not surprisingly) that the field has converged around two ideal-typical views of the mechanisms that lead to coherent action in the world, and these map onto the Type I and Type II distinctions characteristic of DPMs in other domains. We will refer to these these ideal-typical views of action as Type I and Type II culture in action processes.

Type II processes implicate culture in action via intentional, controlled, effortful mechanisms, premised on planning and goal-setting prior to action. This ideal type aligns with Parsonian models wherein actors are reflexively aware of reasoning in the process of execution and the specific intentions of action (Campbell 2009; Archer 2010); these models are also consistent with "bounded" rational action approaches popular among sociologists (e.g., Hedström 2005). Alternatively, Type I processes involve culture in action via the automatic eliciting of action schemata durably (via repeated past experiences in Type I cultural learning processes) associated with the perception of affordances in a situation (Bourdieu 1990). This culture in action process is generally unreflective (although it could be brought to conscious awareness), and relatively effortless.

Note that this distinction is orthogonal to the goal directedness (so-called "purposive") dimension of action. In contrast to the Parsonian bias, in which only Type II 
culture in action processes are seen as "voluntaristic" and "goal directed" (Whitford 2002), the evidence suggests that both Type I and Type II culture in action may be evoked as part of a means-ends problem solving process, as convergent evidence noted in the culture in thinking section above suggests. Because people learn, store, and use culture via either of these two pathways (as we describe above) such that action produced via the associative linkage of situational affordances and available action schemata, is as "cultural" as action that is driven via the formation of "implementation intentions" that draw on the "values" (shared conceptions of the desirable) and is subject to "norms" (shared rules prescribing or proscribing means to reach those goals) characteristic of a given institutional or social setting (Patterson 2014).

Accordingly, it is the degree of effort, controllability, automaticity, and awareness involved in action initiation and action execution that becomes a main analytical (and, from the actor's perspective, phenomenological) differentiating factor between Type I and Type II culture in action processes (Bargh and Chartrand 1999). For instance, Silver (2011) argues that some actions, fitting the prototype of the classic Parsonian schema, require purposeful (and presumably "reflexive") effort, where one has to make oneself "perform." He also notes that a different class of actions (which fall under the Type I culture in action process) are actually elicited by the qualitative affordances ("moodiness") of the situation and thus do not require (nor are they experienced) as effortful. These actions may also, incidentally, constitute the bulk of the empirically observable actions that individuals perform in everyday life, as habit theorists have known for a long time (see Wood and Neal 2007 for the empirical evidence).

Despite variation in the degree of effort required to act, both Type I and Type II culture in action processes can be precipitated by intention. One can willingly choose to enact or to put oneself in a situation that elicits Type I culture in action just as one can choose to step back from the situation and use Type II culture to formulate a plan of action. However, in particularly problematic situations, an actor may unintentionally be constrained 
to follow a line of action precipitated by a Type I process despite having formed a previous intention to act through deliberate and reflexive Type II process. This would manifest when an actor attempts to engage action in particular ways but because of embodied habits unintentionally enacts other forms of action (Wood and Neal 2007).

Type II culture in action is not only the most effortful, but is also comparatively slow, subject to the working memory bottleneck (Martin 2010), and thus more difficult to implement successfully in practical contexts (Campbell 2009). Type II processes require more deliberate attention for enacting the specific scripts of action and as such are more vulnerable to subversion by exigencies and contingencies of the situation. Type II culture in action prototypically takes the form of consciously guiding oneself through various steps in order to reach an outcome (Parsons 1935). This is the type of culture in action that is subject to akrasia (weakness of the will), adaptive preferences, belief distortions, and other so-called "subversions of rationality" (Elster 1984). The latter is a theoretically myopic use of the word "rational," as Type I culture in action processes may partake of their own form (in some contexts superior) of "practical reason" (Bourdieu 1990).

Because action-schemata associated with Type I culture in action are directly activated by affordances in the situation, Type I culture in action processes generally occur effortlessly, and are more likely to be resistant to situational contingencies, distractions, or competing influences outside of the actor's control than Type II action processes. Because of this, there are important asymmetries in the operation of Type I and Type II culture in action processes. Essentially, action-schemata elicited via Type I processes will always be "ready to hand" for a given actor in a given context regardless of intention to act. The only requirements is that the agent perceive the affordances, and that an action schema appropriate to such an affordance (developed via either Type I or Type II cultural learning processes) is available in long term memory. Of course, if a given course of action is elicited automatically via a Type I process, actors may draw on Type II cultural resources (if made available via a learning process) to either modify, redirect or stop this ongoing action process 
presuming that the motivation, resources, and capacity are present.

Research on culture in action DPMs suggests that whether Type I and Type II culture in action processes operate in concert, independently, or at cross-purposes is an empirical, not an analytical, issue. Here we remain as theoretically agnostic as possible, noting that the extant evidence points to all three empirical possibilities depending on situational, interpersonal, intrapersonal and even institutional features. For instance, in some situations, despite the effort to mobilize culture in action via Type II processes, one may unintentionally enact, once again no less "cultural," Type I habits, dispositions, or impulses. These action-control conflicts are not (as framed in the psychoanalytic tradition; e.g., Freud [1927] 2010) between "culture" and "not culture" (e.g., "biology") but between two analytically different types of culture at the personal level.

It is thus important for cultural analysts to differentiate between these two culture in action processes in order to better specify their inter-relationship. This should be done with an eye towards illuminating how situational/environmental conditions can encourage action through the use of one modality or the other. In the same way, and in contrast to "linked systems" formulations which propose a one-to-one correspondence between learning, storage, thinking, and action processes (e.g., such that Type I thinking processes always generate Type I action processes; see Van Bavel et al. 2012 for a related critique) we propose that both thinking and acting do not always align with respect to the use of Type I and Type II culture and, in fact, they can become disassociated or combined in empirically distinct ways.

\section{Discussion and Conclusions}

In this paper, we clarified the key components of specific models emerging from a common dual process framework (DPF). This is a now largely uncontroversial approach to cognition across a variety of disciplines, from social and cognitive psychology to neuroscience and anthropology, and increasingly (see figure 1) sociology. We suggested that 
debates among sociologists regarding the merits of dual process models can benefit from a more nuanced understanding of what exactly dual process models are. We also noted that the DPF-our term for a broad theoretical perspective that is now widely accepted across the social and behavioral sciences-needs to be distinguished from more specific applications of the framework to particular domains, which we referred to as dual process models (DPMs). In this sense, DPMs are located at a "lower level" on Alexander's ([1982] 2014) epistemic continuum (see Figure 2). Specifically, we suggest that different dual process models are applicable to analytically and empirically distinct cognitive processes and pragmatic tasks. We also identified how four key phases of the enculturation process can be characterized from a DPF perspective: in each case, there are separate Type I and Type II modalities (see Table 1) of these processes in given settings. We specify these four domains as encompassing learning, storing, processing/thinking, and acting. In what follows we summarize the implications of this discussion for relevant work in cultural sociology.

In terms of how DPMs apply to learning, we began with the supposition that cultural learning is indispensable to cognitive development. Unlike most sociological accounts, however, we are explicit that there is no single learning process. We delineate two broad types of learning, Type I and Type II. The former refers to an implicit process whereby learning is less effortful, occurs more or less automatically, but is slow and requires multiple repetitions. Type II learning refers to a process that involves the conscious exertion of effort, and is deployed in delimited instances marked by specific, temporally bounded learning goals. The early stages of mastering one of Chopin's etudes for piano requires deliberate and painstakingly effortful learning of the Type II variety, arguably for most keyboardists, while the pianist's lengthy journey from novice to technical master involves the slow, gradual accretion of embodied skills and rapid-fire associations through repeated practice, i.e., Type I learning (see Sudnow 1978).

The next domain of the dual process model we propose is that of memory, which, we emphasize, is more of a state than a process. Memory comes in two varieties, declarative and 
nondeclarative, which again map onto our Type I and Type II distinction. Declarative memory, on the one hand, involves the mental storage of episodic, semantic, or autobiographical information, while nondeclarative memory, on the other, stores discursively inaccessible "know-how" regarding procedures and associative dispositions. We can distinguish here between "knowing that" Jefferson City is the capital of Missouri, and "knowing how" to look up state capitals with a search engine. The latter, nondeclarative form of memory also stores implicit attitudinal or evaluative associations, such as unarticulated assumptions regarding gender, racial, ethnic, or other identity categories (Shepherd 2011). We advocate that cultural researchers specify the cultural learning and storage types they are examining, rather than assuming the enculturation process is monolithic and undifferentiated. Differentiating the two types of the storage of culture will afford future studies greater clarity about what culture is actually doing, and how and where it is done.

We argued that an important third domain was thinking, or the processing of stored cultural information. Type I corresponds to associative, automatic processing, while Type II involves slower, deliberate rule-based reasoning. Type I processing involves tasks such as pattern completion or similarity-based retrieval of stored cultural knowledge that has been acquired and stored through gradual Type I enculturation or enskilment (Pálsson 1994). Type II processing involves the retrieval of encoded symbols for practical tasks such as reasoning, planning, justifying, and designing (Leschziner and Green 2013). This latter type of cognitive processing is slower than "rapid-fire" associative processing because it involves the manipulation of discrete parcels of information. Our cognitive ability to do so is limited to dealing with approximately four "chunks" at a time (give or take one). Knowledge about rule-based Type II processing is useful for cultural analysis in that it helps researchers pinpoint how actors deliberate and make decisions in everyday situations. However, recent sociological research that references dual process models of cognition tends to assume that the distinction between Type I and II processing is fluid (e.g., Leschziner and Green 2013). 
We wish to emphasize the distinctness of the two types, however, as research in cognitive and social psychology has emphasized (Smith and DeCoster 2000).

The final domain we describe is that of action, which we analytically disassociate from thinking or processing. We find that, with some exceptions, much of contemporary analysis of culture in action is, more accurately, analysis of culture in thinking. We noted that it is important to put more emphasis on the actual doing involved in culturally inflected action while respecting the analytical autonomy of the other DPMs and their relevance for cultural analysis. In the DPM of culture in action, Type I action involves relatively effortless, habitual activities requiring little conscious attention and done in generally efficient ways. Almost any routine or familiar task will suffice as an example. Type II action entails intentional efforts to realize specific intentions or goals, themselves often resulting from Type II rule-based processing. Of course, many actions broadly conceived that require a great deal of effort — such as forcing oneself to get ready to leave the house on a rainy morning-involve a number of smaller, effortlessly executed routine tasks (see Danna Lynch 2011 for an application of this distinction to role enactment processes). Additionally, actions that are deliberately executed at one temporal point may become routine and automatic at later junctures. Nevertheless, it behooves analysts to differentiate these separate types of action when developing cultural theory or making sense of empirical materials (e.g. observations "on" action).

More broadly, we argue that it is time to move beyond general debates about the overall validity or appropriateness of applying dual process models to social phenomena. As a scientific consensus has been reached regarding this broad framework in the cognitive and social sciences (and has been implicitly employed in sociological explanation since the advent of the "classics"), it is more productive to debate the merits of applying particular dual process models to specific analytical and empirical realms (e.g. reasoning, morality, action, etc.), and to specify the role social processes and mechanisms to discussions regarding the precise relationships among particular domains of the various dual process models 
(Shepherd 2011). Whether cultural analysts conceive of culture as internalized values (Parsons 1935), socially derived categories (Durkheim [1915] 2008), semiotic codes (Alexander 2003), or as repertoires of skills and strategies that funnel and facilitate action (Swidler 2001), extant research regarding cultural elements and processes can be further extended and clarified by incorporating insights from specific dual process models. By employing the appropriate dual process models, the relationship between particular methodological strategies and the empirical results that they yield can be better specified. 


\section{References}

Abramson, Corey M. 2012. "From 'Either-Or' To 'When and How': A Context-Dependent Model of Culture in Action." Journal for the Theory of Social Behaviour 42(2):155-80.

Alexander, Jeffrey C. [1982] 2014. Theoretical Logic in Sociology. Vol. 1, Positivism, Presuppositions, and Current Controversies. New York: Routledge.

Alexander, Jeffrey C. 2003. The Meanings of Social Life: A Cultural Sociology. Oxford: Oxford University Press.

Archer, Margaret S. 2010. "Routine, Reflexivity, and Realism.” Sociological Theory 28: 272-303.

Bargh, John A. and Tanya L. Chartrand. 1999. "The Unbearable Automaticity of Being." American Psychologist 54(7):462-79.

Barsalou, Lawrence W. 1999. "Perceptual Symbol Systems." Behavioral and Brain Sciences 22(4):577-660.

Baumeister, Roy F., Ellen Bratslavsky, Mark Muraven, and Dianne M. Tice. 1998. "Ego Depletion: Is the Active Self a Limited Resource?" Journal of Personality and Social Psychology 74(5):1252-65.

Berger, Peter L. and Thomas Luckmann. 1966. The Social Construction of Reality: A Treatise in the Sociology of Knowledge. New York: Penguin Books.

Bloch, Maurice. 1998. How We Think They Think: Anthropological Approaches to Cognition, Memory, and Literacy. Boulder, CO: Westview Press.

Bloch, Maurice. 1991. “Language, Anthropology And Cognitive Science.” Man 26(2):183-98.

Bourdieu, Pierre. 1990. The Logic of Practice. Translated by R. Nice. Stanford, CA: Stanford University Press.

Breen, Richard, Ruud Luijkx, Walter Müller, and Reinhard Pollak. 2009. "Nonpersistent Inequality in Educational Attainment: Evidence from Eight European Countries." American Journal of Sociology 114: 1475-1521.

Brewer, William F. 1986. "What Is Autobiographical Memory?” Pp. 25-49 in Autobiographical Memory, edited by W. F. Brewer. Cambridge: Cambridge University Press.

Brewer, Marilynn B. 1988. "A Dual Process Model of Impression Formation.” Pp. 1-36 in Advances in Social Cognition, edited by T. K. Srull and R. S. Wyer, Jr. New York: Taylor and Francis. 
Burwell, Rebecca D. and Furtak, Sharon. C., 2008. Recognition memory: can you teach an old dogma new tricks?. Neuron, 59(4), pp.523-525.

Campbell, Colin. 2009. "Distinguishing the Power of Agency from Agentic Power: A Note on Weber and the 'Black Box' of Personal Agency.” Sociological Theory 27(4):407-18.

Cerulo, Karen A. 2010. "Mining the Intersections of Cognitive Sociology and Neuroscience." Poetics 38(2):115-32.

Chaiken, Shelly and Yaacov Trope. 1999. Dual Process Theories in Social Psychology. New York: Guilford Press.

Chauvel, Guillaume, François Maquestiaux, Eric Ruthruff, André Didierjean, and Alan A. Hartley. 2012. "Novice Motor Performance: Better Not to Verbalize." Psychonomic Bulletin \& Review 20(1):177-83.

Cohen, Michael D. and Paul Bacdayan. 1994. "Organizational Routines Are Stored As Procedural Memory: Evidence from a Laboratory Study." Organization Science 5(4):554-68.

Cohen, Neil J. and Larry R. Squire. 1980. "Preserved Learning and Retention of Pattern-Analyzing Skill in Amnesia: Dissociation of Knowing How and Knowing That." Science 210(4466):207-10.

Conway, Martin. 1995. Flashbulb Memories. East Sussex, UK: Lawrence Erlbaum.

Conway, Martin A. and Christopher W. Pleydell-Pearce. 2000. "The Construction of Autobiographical Memories in the Self-Memory System." Psychological Review 107(2):261-88.

Cunningham, William A. and Philip David Zelazo. 2007. "Attitudes And Evaluations: a Social Cognitive Neuroscience Perspective.” Trends in Cognitive Sciences 11(3):97-104.

Danna Lynch, Karen. 2007 "Modeling Role Enactment: Linking Role Theory and Social Cognition." Journal for the Theory of Social Behaviour 37(4): 379-99.

Dietrich, Arne. 2004. "Neurocognitive Mechanisms Underlying the Experience of Flow." Consciousness and Cognition 13(4):746-61.

D'Andrade, Roy G. 1981. “The Cultural Part of Cognition.” Cognitive Science 5: 179-195.

DiMaggio, Paul. 1997. "Culture and Cognition." Annual Review of Sociology. 23(1):263-87.

DiMaggio, Paul. 2002. "Why Cognitive (and Cultural) Sociology Needs Cognitive Psychology." Pp. 274-82 in Culture in Mind: Toward a Sociology of Culture and Cognition, 
edited by K. A. Cerulo. New York: Routledge.

Douglas, Mary. 1966. Purity And Danger: An Analysis of Concepts of Pollution and Taboo. New York: Routledge.

Douglas, Mary. 1986. How Institutions Think. Syracuse, NY: Syracuse University Press.

Duneier, Mitchell. 1999. Sidewalk. New York: Farrar, Straus and Giroux.

Durkheim, Émile. [1915] 2008. The Elementary Forms of the Religious Life. Translated by J. W. Swain. Mineola, NY: Dover Publications.

Eccles, Jacquelynne S. and Allan Wigfield. 2002. "Motivational Beliefs, Values, And Goals." Annual Review of Psychology. 53(1):109-32.

Eliasoph, Nina and Paul Lichterman. 2003. "Culture in interaction." American Journal of Sociology 108(4): 735-794.

Elster, Jon. 1984. Ulysses And the Sirens: Studies in Rationality and Irrationality. Cambridge: Cambridge University Press.

Evans, Jonathan St. B. T. and Keith E. Stanovich. 2013. "Dual-Process Theories Of Higher Cognition: Advancing the Debate.” Perspectives on Psychological Science 8(3):223-41.

Evans, Jonathan St. B. T. 2008. "Dual-Processing Accounts Of Reasoning, Judgment, and Social Cognition." Annual Review of Psychology 59(1):255-78.

Ferguson, Melissa J. and John A. Bargh. 2004. "How Social Perception Can Automatically Influence Behavior." Trends in Cognitive Sciences 8(1):33-39.

Fishbein, Martin and Icek Ajzen. 2011. Predicting and Changing Behavior: The Reasoned Action Approach. New York: Psychology Press.

Freud, Sigmund. [1927] 2010. The Ego and the Id. Mansfield Centre, CT: Martino Publishing.

Frye, Margaret. 2012. "Bright Futures In Malawi's New Dawn: Educational Aspirations as Assertions of Identity." American Journal of Sociology 117(6):1565-1624.

Fu, Wai-Tat and John R. Anderson. 2008. "Dual Learning Processes in Interactive Skill Acquisition." Journal of Experimental Psychology: Applied 14(2):179-91.

Gawronski, Bertram and Galen V. Bodenhausen. 2011. "The Associative-Propositional Evaluation Model: Theory, Evidence, and Open Questions." Advances in Experimental Social Psychology 44:59-127.

Geertz, Clifford. 1973. The Interpretation of Cultures: Selected Essays. New York: Basic Books. 
Glenberg, Arthur M. 1997. "What Memory Is for: Creating Meaning in the Service of Action." Behavioral and Brain Sciences 20(1):41-50.

Goffman, Erving. 1989. "On Fieldwork." Journal of Contemporary Ethnography 18(2):123-32.

Greenwald, Anthony G., T. Andrew Poehlman, Eric Luis Uhlmann, and Mahzarin R. Banaji. 2009. "Understanding And Using the Implicit Association Test: III. Meta-Analysis of Predictive Validity." Journal of Personality and Social Psychology 97(1):17-41.

Gross, Neil. 2009. "A Pragmatist Theory Of Social Mechanisms.” American Sociological Review 74(3):358-79.

Hagger, Martin S., Chantelle Wood, Chris Stiff, and Nikos L. D. Chatzisarantis. 2010. "Ego Depletion and the Strength Model of Self-Control: A Meta-Analysis." Psychological Bulletin 136(4):495-525.

Haidt, Jonathan. 2001. "The Emotional Dog and Its Rational Tail: A Social Intuitionist Approach to Moral Judgment.” Psychological Review 108(4):814-34.

Haidt, Jonathan. 2004. “The Emotional Dog Gets Mistaken For a Possum.” Review of General Psychology 8(4):283-90.

Haidt, Jonathan. 2005. "Invisible Fences of the Moral Domain." Behavioral and Brain Sciences 28(04):552-53.

Hedström, Peter. 2005. Dissecting the Social: On the Principles of Analytical Sociology. New York: Cambridge University Press.

Hendricks, Michelle A., Christopher M. Conway, and Ronald T. Kellogg. 2013. "Using Dual-Task Methodology to Dissociate Automatic from Nonautomatic Processes Involved in Artificial Grammar Learning." Journal of Experimental Psychology: Learning, Memory, and Cognition 39(5):1491-1500.

Hoffmann, John P. 2014. "Religiousness, Social Networks, Moral Schemas, and Marijuana Use: A Dynamic Dual-Process Model of Culture and Behavior.” Social Forces 93(1):181-208.

Ignatow, Gabriel. 2009. "Culture And Embodied Cognition: Moral Discourses in Internet Support Groups for Overeaters." Social Forces 88(2):643-69.

Inglehart, Ronald. 2006. "Mapping Global Values.” Comparative Sociology 5(2):115-36.

Jerolmack, Colin and Shamus Khan. 2014. "Talk Is Cheap: Ethnography And the Attitudinal Fallacy." Sociological Methods \& Research 43(2):178-209.

Katz, Irwin and R. Glen Hass. 1988. "Racial Ambivalence and American Value Conflict: 
Correlational and Priming Studies of Dual Cognitive Structures." Journal of Personality and Social Psychology 55(6):893-905.

Khan, Shamus Rahman. 2011. Privilege: The Making of an Adolescent Elite at St. Paul's School. Princeton, NJ: Princeton University Press.

Knorr-Cetina, Karin. 2014. "Intuitionist Theorizing." Pp. 29-60 in Theorizing In Social Science: the Context of Discovery, edited by R. Swedberg. Stanford, CA: Stanford University Press.

Krämer, Walter. 2013. "Kahneman, D. (2011): Thinking, Fast And Slow.” Statistical Papers 55(3):915-15.

Lamont, Michèle. 1992. Money, Morals, and Manners: The Culture of the French and the American Upper-Middle Class. Chicago: University Of Chicago Press.

Lamont, Michèle. 2012. "Toward a Comparative Sociology Of Valuation and Evaluation." Annual Review of Sociology 38(1):201-21.

Lamont, Michèle and Ann Swidler. 2014. "Methodological Pluralism and the Possibilities and Limits of Interviewing." Qualitative Sociology 37(2):153-71.

Laughlin, Charles D., John McManus, and Eugene G. D'Aquili. 1992. Brain, Symbol \& Experience: Toward a Neurophenomenology of Human Consciousness. New York: Columbia University Press.

Lee, Yuh-Shiow. 1995. "Effects Of Learning Contexts on Implicit and Explicit Learning." Memory \& Cognition 23(6):723-34.

Leschziner, Vanina and Adam Isaiah Green. 2013. "Thinking About Food and Sex: Deliberate Cognition in the Routine Practices of a Field." Sociological Theory 31(2):116-44.

Lizardo, Omar and Michael Strand. 2010. "Skills, Toolkits, Contexts and Institutions: Clarifying the Relationship between Different Approaches to Cognition in Cultural Sociology." Poetics 38(2):205-28.

Longest, Kyle C., Steven Hitlin, and Stephen Vaisey. 2013. "Position And Disposition: The Contextual Development of Human Values." Social Forces 91(4):1499-1528.

McClelland, James L., Bruce L. Mcnaughton, and Randall C. O'reilly. 1995. "Why There Are Complementary Learning Systems in the Hippocampus and Neocortex: Insights from the Successes and Failures of Connectionist Models of Learning and Memory." Psychological Review 102(3):419-57.

Maquestiaux, François, Maude Laguë-Beauvais, Eric Ruthruff, Alan Hartley, and Louis 
Bherer. 2010. "Learning To Bypass the Central Bottleneck: Declining Automaticity with Advancing Age." Psychology and Aging 25(1):177-92.

Margolis, Howard. 1987. Patterns, Thinking, and Cognition: a Theory of Judgment. Chicago: University of Chicago Press.

Martin, John Levi. 2010. "Life's a Beach but You're an Ant, and Other Unwelcome News for the Sociology of Culture." Poetics 38(2):229-44.

Miles, Andrew. 2014. "Addressing The Problem of Cultural Anchoring: An Identity-Based Model of Culture in Action." Social Psychology Quarterly 77(2):210-27.

Miller, George A. 1956. "The Magical Number Seven, plus or Minus Two: Some Limits on Our Capacity for Processing Information.” Psychological Review 101(2):63:81-97.

Mische, 2010. "Finding the Future in Deliberative Process: A Pragmatist Critique of the Dual-Process Model." Presented at the Meeting of the Social Science History Association, Chicago, November 2010.

Moors, Agnes and Jan De Houwer. 2006. "Automaticity: A Theoretical And Conceptual Analysis." Psychological Bulletin 132(2):297-326.

Pagis, Michal. 2010. "Producing Intersubjectivity in Silence: An Ethnographic Study of Meditation Practice.” Ethnography 11(2):309-28.

Pálsson, Gisli. 1994. “Enskilment At Sea.” Man 29(4):901-27.

Parker, Sue Taylor and Michael L. McKinney. 1999. Origins of Intelligence: The Evolution of Cognitive Development in Monkeys, Apes, and Humans. Baltimore, MD: The Johns Hopkins University Press.

Parsons, Talcott. 1935. “The Place Of Ultimate Values in Sociological Theory.” International Journal of Ethics 45(3):282-316.

Parsons, Talcott. 1951. The Social System. Glencoe, IL: Free Press.

Patterson, Orlando. 2014. "Making Sense Of Culture.” Annual Review of Sociology 40(1):1-30.

Polanyi, Michael. 1958. Personal Knowledge: Towards a Post-Critical Philosophy. Chicago: University of Chicago Press.

Polanyi, Michael. [1966]2009. The Tacit Dimension. Chicago: Chicago University Press.

Pugh, Alison J. 2013. "What Good are Interviews for Thinking about Culture?: Demystifying Interpretive Analysis." American Journal of Cultural Sociology 1(1):42-68.

Reber, Arthur. 1993. Implicit learning and tacit knowledge: An essay on the cognitive unconscious. New 
York: Oxford University Press.

Ryle, Gilbert. 2002. The Concept of Mind. London: Routledge.

Sallaz, Jeffrey J. and Jane Zavisca. 2007. "Bourdieu in American sociology, 1980-2004." Annual Review of Sociology 33: 21-41.

Schacter, Daniel L. 1987. "Implicit Memory: History and Current Status.” Journal of Experimental Psychology: Learning, Memory, and Cognition 13(3):501-18.

Schwartz, Shalom. 2012. "Toward Refining the Theory of Basic Human Values.” Pp. $39-46$ in Methods, Theories, and Empirical Applications in the Social Sciences, edited by S. Salzborn, E. Davidov, and J. Reinecke. Berlin: Springer VS.

Shepherd, Hana. 2011. "The Cultural Context of Cognition: What the Implicit Association Test Tells Us About How Culture Works.” Sociological Forum 26(1): 121-43.

Shore, Bradd. 1996. Culture In Mind: Cognition, Culture, and the Problem of Meaning. New York: Oxford University Press.

Silver, Daniel. 2011. “The Moodiness Of Action.” Sociological Theory 29(3):199-222.

Slotnick, S.D. and Dodson, C.S., 2005. Support for a continuous (single-process) model of recognition memory and source memory. Memory \& Cognition, 33(1), pp.151-170.

Smith, Eliot R. and Jamie DeCoster. 2000. "Dual-Process Models in Cognitive Psychology: Conceptual Integration and Links to Underlying Memory Systems." Personality and Social Psychology Review 4(2):108-131.

Squire, Larry R. 1992. "Declarative And Nondeclarative Memory: Multiple Brain Systems Supporting Learning and Memory." Journal of Cognitive Neuroscience 4(3):232-43.

Srivastava, Sameer B. and Mahzarin R. Banaji. 2011. "Culture, Cognition, And Collaborative Networks in Organizations." American Sociological Review 76(2):207-33.

Steele, Claude M. and Joshua Aronson. 1995. "Stereotype Threat and the Intellectual Test Performance of African Americans." Journal of Personality and Social Psychology 69(5):797-811.

Stoltz, Dustin S. and Marshall A. Taylor. 2015. "Purposeful Enunciation of Material Culture: Cognition, Materiality, and Illiquidity as Protest." Paper presented at the 40th Annual Meeting of the Social Science History Association, Baltimore, MD, November 2015.

Strack, Fritz and Roland Deutsch. 2004. "Reflective And Impulsive Determinants of Social Behavior." Personality and Social Psychology Review 8(3):220-47. 
Strauss, Claudia and Naomi Quinn. 1997. A Cognitive Theory of Cultural Meaning. New York: Cambridge University Press.

Sudnow, David. 1978. Ways of the Hand: The Organization of Improvised Conduct. Cambridge, MA: MIT Press.

Summers-Effler, Erika. 2010. Laughing Saints and Righteous Heroes: Emotional Rhythms in Social Movements. Chicago: University of Chicago Press

Summers-Effler, Erika, Justin Van Ness, and Christopher Hausmann. 2015. "Peeking In the Black Box: Studying, Theorizing, and Representing the Micro-Foundations of Day-to-Day Interactions." Journal of Contemporary Ethnography 44(4):450-79.

Sun, Ron, Paul Slusarz, and Chris Terry. 2005. "The Interaction Of the Explicit and the Implicit in Skill Learning: A Dual-Process Approach." Psychological Revien 112(1):159-92.

Swidler, Ann. 2001. Talk of Love: How Culture Matters. Chicago: University of Chicago Press.

Swidler, Ann. 2008. “Comment On Stephen Vaisey’s 'Socrates, Skinner, and Aristotle: Three Ways of Thinking About Culture in Action."' Sociological Forum 23(3):614-18.

Talarico, Jennifer M. and David C. Rubin. 2003. "Confidence, Not Consistency, Characterizes Flashbulb Memories.” Psychological Science 14(5):455-61.

Tomasello, Michael. 1999. The Cultural Origins of Human Cognition. Cambridge, MA: Harvard University Press.

Tulving, Endel and Daniel L. Schacter. 1990. "Priming And Human Memory Systems." Science 247(4940):301-6.

Tulving, Endel. 1983. Elements Of Episodic Memory. Oxford: Clarendon Press.

Turner, Stephen. 2007. "Social Theory as a Cognitive Neuroscience." European Journal of Social Theory 10(3):357-74.

Vaisey, Stephen and Omar Lizardo. 2010. "Can Cultural Worldviews Influence Network Composition?” Social Forces 88(4):1595-1618.

Vaisey, Stephen. 2010. "What People Want: Rethinking Poverty, Culture, And Educational Attainment." The ANNALS of the American Academy of Political and Social Science 629(1):75-101.

Vaisey, Stephen. 2009. "Motivation And Justification: A Dual-Process Model of Culture in Action." American Journal of Sociology 114(6):1675-1715. 
Vaisey, Stephen. 2008. "Socrates, Skinner, And Aristotle: Three Ways of Thinking About Culture in Action." Sociological Forum 23(3):603-13.

Van Bavel, Jay J., Yi Jenny Xiao, and William A. Cunningham. 2012. "Evaluation is a Dynamic Process: Moving Beyond Dual System Models." Social and Personality Psychology Compass 6(6):438-54.

Vila-Henninger, Luis Antonio. 2015. "Toward Defining The Causal Role of Consciousness: Using Models of Memory and Moral Judgment from Cognitive Neuroscience to Expand the Sociological Dual-Process Model." Journal for the Theory of Social Behaviour 45(2):238-60.

Wacquant, Loïc J. D. 2004. Body \& Soul: Notebooks of an Apprentice Boxer. Oxford: Oxford University Press.

Walsh, Katherine Cramer. 2004. Talking About Politics: Informal Groups and Social Identity in American Life. Chicago: University of Chicago Press.

Whitehouse, Harvey. 2004. Modes Of Religiosity: a Cognitive Theory of Religious Transmission. Walnut Creek, CA: AltaMira Press.

Whitford, Josh. 2002. "Pragmatism and the Untenable Dualism of Means and Ends: Why Rational Choice Theory Does Not Deserve Paradigmatic Privilege." Theory and Society 31(3):325-63.

Wilson, Timothy D., Samuel Lindsey, and Tonya Y. Schooler. 2000. “A Model of Dual Attitudes." Psychological Review 107(1):101-26.

Wood, Wendy and David T. Neal. 2007. "A New Look at Habits and the Habit-Goal Interface.” Psychological Review 114(4):843-63.

Yam, Kai Chi, Xiao-Ping Chen, and Scott J. Reynolds. 2014. "Ego Depletion and Its Paradoxical Effects on Ethical Decision Making." Organizational Behavior and Human Decision Processes 124(2):204-14. 